\title{
Aplikasi Deteksi Dini Defisiensi Mineral Mikro pada Manusia Berbasis Web
}

\author{
Nina Sevani*1, Rheinhard Unwaru ${ }^{2}$ \\ 1,2Program Studi Teknik Informatika, FTIK Ukrida, Jakarta \\ e-mail: *11nina.sevani@ukrida.ac.id, ${ }^{2}$ rheinhard.unwaru@ @ivitas.ukrida.ac.id
}

\begin{abstract}
Abstrak
Kekurangan gizi menjadi salah satu masalah yang dialami oleh masyarakat Indonesia, khususnya defisiensi mineral mikro. Pada dasarnya hal ini dikarenakan kurangnya pemahaman masyarakat akan pentingnya pola konsumsi makanan seimbang serta kemiskinan yang dialami oleh sebagian masyarakat sehingga mereka sulit memenuhi asupan gizi setiap hari dan sulit menemui seorang ahli atau dokter gizi.

Hal ini dapat diatasi melalui pembuatan sebuah aplikasi berbasis web yang mampu mendeteksi defisiensi mineral mikro pada manusia secara dini, serta memberikan saran untuk mengatasi defisiensi tersebut. Aplikasi ini menggunakan sekumpulan data sebagai basis pengetahuan yang diperoleh dari studi pustaka dan diskusi dengan pakar gizi. Pengetahuan direpresentasikan dalam bentuk rule-based system dan diolah dengan metode forward chaining.

Aplikasi ini dapat diakses dan digunakan oleh pengguna melalui internet. Pembuatan aplikasi ini dapat membantu masyarakat dalam menyadari pentingnya asupan mineral mikro dalam tubuh dan juga mendorong mereka untuk memiliki kebiasaan hidup yang sehat.
\end{abstract}

Kata kunci-gizi, mineral, aplikasi web, rule-based, forward chaining.

Abstract
Malnutrition is the one of the Indonesian society issues, especially micro mineral deficiency. Basically, this is due to a lack of society understanding of the importance of balanced food consumtion patterns and poverty factor in Indonesia so that they are difficult to fulfill the daily nutritional intake and also difficult to meet a doctor or nutrition expert.

This can be overcome through the creating of a web-based application which can detecting micro mineral deficiency in the human body at the early stage, as well as providing suggestions to overcome those deficiency. This application uses a set of data as a knowledge base which obtained from the literature and discussions with nutritional experts. The knowledge is represented with a rule-based system and processed with forward chaining method.

This application can be accessed and used by users via internet. This application can helps the society to realize the importance of micro mineral intake and also encourage them to have healthy life habits.

Keywords - nutrient, mineral, web application, rule-based, forward chaining. 


\section{PENDAHULUAN}

$\mathrm{Z}$ at gizi merupakan suatu substansi kimia yang diperlukan oleh tubuh untuk melakukan fungsinya, yaitu menghasilkan energi, membangun dan memelihara jaringan tubuh, serta mengatur berbagai proses kehidupan, seperti pertumbuhan dan pemeliharaan kesehatan [1]. Kekurangan gizi di Indonesia, khususnya defisiensi mineral mikro menyebabkan sebagian masyarakat mengalami gangguan kesehatan. Defisiensi mineral mikro, seperti besi (Fe), seng (Zn), iodium (I), dan fluor (F) banyak terjadi di wilayah Indonesia.

Penelitian [2] melaporkan bahwa sekitar 138 juta masyarakat Indonesia mengalami defisiensi iodium, serta pada penelitian [3] juga melaporkan bahwa pada tahun 2008 teridenifikasi sebanyak 316 masyarakat Indonesia mengalami gangguan kesehatan akibat defisiensi iodium. Kekurangan asupan iodium dapat menyebabkan gangguan pada perkembangan otak anak yang nantinya akan mengakibatkan penurunan tingkat kecerdasannya [4]. Dalam artikel [5] dicatat bahwa 12,7\% anak usia 5 -12 tahun mengalami anemia. Penyakit anemia diakibatkan defisiensi besi dalam tubuh seseorang. Selain itu, penelitian [6] melaporkan bahwa asupan mineral seng (zinc) pada masyarakat Indonesia masih memprihatinkan, serta dalam penelitian [7] dilaporkan bahwa wilayah Kalimantan Barat memiliki tingkat karies gigi yang tinggi akibat defisiensi fluor. Defisiensi mineral mikro tersebut terjadi karena sebagian masyarakat belum mengetahui penyebab penyakit defisiensi mineral yang dialami dan solusi pencegahan atau pun pengobatannya. Terlebih lagi, sebagian masyarakat tidak mampu melakukan konsultasi dan pengobatan kepada seorang dokter gizi secara langsung.

Dalam artikel [8] dan [9] dipaparkan bahwa teknologi komputer dapat dimanfaatkan untuk meningkatkan layanan kesehatan kepada masyarakat melalui aplikasi yang dapat melakukan diagnosa. Aplikasi tersebut umumnya berupa sistem komputer yang mampu mengetahui dan menganalisis gejala gangguan kesehatan pada pasien dan kemudian memberikan anjuran langsung terhadap pasien [10]. Aplikasi dengan kemampuan tersebut dikenal sebagai sistem berbasis pengetahuan, dimana kecerdasan yang dimiliki oleh pakar dimasukkan ke dalam komputer, sehingga sistem dapat melakukan pekerjaan seperti yang dapat dilakukan oleh manusia (pakar) [11].

Oleh karena itu, masalah di atas dapat diatasi dengan membuat sebuah aplikasi yang mampu mendeteksi secara dini defisiensi mineral mikro dalam tubuh manusia melalui gejala gangguan fisik yang dialami, serta mampu memberikan saran berupa jenis makanan yang tepat untuk mengatasi defisiensi tersebut. Aplikasi deteksi dini ini dapat membantu mengenal kemungkinan dialaminya defisiensi mineral mikro tanpa perlu datang kepada pakar atau dokter gizi terlebih dahulu. Selain itu, aplikasi ini dibuat berbasis web agar dapat diakses secara online melalui media internet, sehingga dapat digunakan oleh masyarakat di berbagai wilayah Indonesia.

\section{METODE PENELITIAN}

\subsection{Akuisisi Pengetahuan}

Akuisisi pengetahuan merupakan tahapan pengumpulan, pemindahan, dan transformasi pengetahuan untuk menyelesaikan suatu masalah dari sumber pengetahuan ke dalam komputer. Pengetahuan diperoleh dari studi pustaka dan diskusi dengan seorang dokter spesialis gizi dari RSIA St. Carolus Summarecon Serpong, Tangerang.

\subsubsection{Data Gejala Defisiensi Mineral Mikro}

Data gejala gangguan fisik akibat defisiensi mineral mikro yang diperoleh ditunjukkan pada Tabel 1 .

IJCCS Vol. 8, No. 2, July 2014: $213-222$ 
Tabel 1 Gejala Defisiensi Mineral Mikro

\begin{tabular}{|l|l|}
\hline Kode & \multicolumn{1}{|c|}{ Nama Gejala } \\
\hline G001 & Penglihatan mata berkunang-kunang \\
\hline G002 & Bagian dalam kelopak mata tampak pucat \\
\hline G003 & Nafas terengah-engah \\
\hline G004 & Anemia \\
\hline G005 & 5L (lemah, letih, lesu, lelah, lunglai) \\
\hline G006 & Kulit telapak tangan tampak pucat \\
\hline G007 & Kurang konsentrasi dalam bekerja atau belajar \\
\hline G008 & Rasa gelisah dan perubahan suasana hati \\
\hline G009 & Kuku rapuh \\
\hline G010 & Kerontokan rambut \\
\hline G011 & Daya tahan tubuh berkurang atau menurun \\
\hline G012 & Gangguan penyembuhan luka \\
\hline G013 & Pertumbuhan terhambat \\
\hline G014 & Sulit melihat dalam keadaan gelap \\
\hline G015 & Kurang nafsu makan \\
\hline G016 & Ketajaman indera pengecap berkurang \\
\hline G017 & Nyeri saat menelan makanan \\
\hline G018 & Sering merasa mual dan muntah \\
\hline G019 & Timbul tonjolan kecil pada kelenjar tiroid dan membengkak atau membesar \\
\hline G020 & Kulit terasa kering dan kasar \\
\hline G021 & Nyeri pada sendi dan otot \\
\hline G022 & Tinggal di daerah atau kawasan pegunungan \\
\hline G023 & Karies pada gigi \\
\hline G024 & Tinggal di daerah sulit air bersih \\
\hline
\end{tabular}

\subsubsection{Data Relasi}

Untuk menentukan jenis defisiensi mineral mikro dari masing-masing gejala di atas, maka digunakan data relasi pada Tabel 2.

Tabel 2 Data Relasi

\begin{tabular}{|c|c|c|c|c|}
\hline \multirow{2}{*}{ Kode } & \multicolumn{5}{|c|}{ Jenis Defisiensi Mineral Mikro } \\
\hline & Besi & Seng & Iodium & Fluor \\
\hline G001 & $\mathrm{x}$ & & & \\
\hline G002 & $\mathrm{x}$ & & & \\
\hline G003 & $\mathrm{x}$ & & & \\
\hline G004 & $\mathrm{x}$ & & & \\
\hline G005 & $\mathrm{x}$ & & & \\
\hline G006 & $\mathrm{x}$ & & & \\
\hline G007 & $\mathrm{x}$ & & & \\
\hline G008 & $\mathrm{x}$ & & & \\
\hline G009 & $\mathrm{x}$ & & & \\
\hline G010 & $\mathrm{x}$ & $\mathrm{x}$ & & \\
\hline G011 & $\mathrm{x}$ & $\mathrm{x}$ & & \\
\hline G012 & & $\mathrm{x}$ & & \\
\hline G013 & & $\mathrm{x}$ & & \\
\hline G014 & & $\mathrm{x}$ & & \\
\hline G015 & & $\mathrm{x}$ & & \\
\hline G016 & & $\mathrm{x}$ & & \\
\hline G017 & & & $\mathrm{x}$ & \\
\hline G018 & & & $\mathrm{x}$ & \\
\hline G019 & & & $\mathrm{x}$ & \\
\hline G020 & & & $\mathrm{x}$ & \\
\hline G021 & & & $\mathrm{x}$ & \\
\hline G022 & & & & \\
\hline G023 & & & & \\
\hline G024 & & & & \\
\hline
\end{tabular}




\subsection{Representasi Pengetahuan}

Dalam aplikasi deteksi dini ini, representasi pengetahuan dibuat dalam bentuk rulebased system, dimana pengetahuan disimpan dalam bentuk kaidah atau aturan-aturan if-then dan berjumlah 13 rules. Adapun ke-13 rules yang dimiliki aplikasi ini adalah sebagai berikut:

Rule \#1 IF bagian dalam kelopak mata tampak pucat

THEN defisiensi mineral Besi

Rule \#2 IF timbul tonjolan kecil pada kelenjar tiroid dan membesar

THEN defisiensi mineral Iodium

Rule \#3 IF karies pada gigi

THEN defisiensi mineral Fluor

\subsection{Mekanisme Inferensi}

Mekanisme inferensi dalam aplikasi deteksi dini defisiensi mineral mikro dalam tubuh berbasis web ini menggunakan metode forward chaining. Aliran mekanisme inferensi dalam aplikasi ini dapat ditunjukkan pada Gambar 1 berikut:

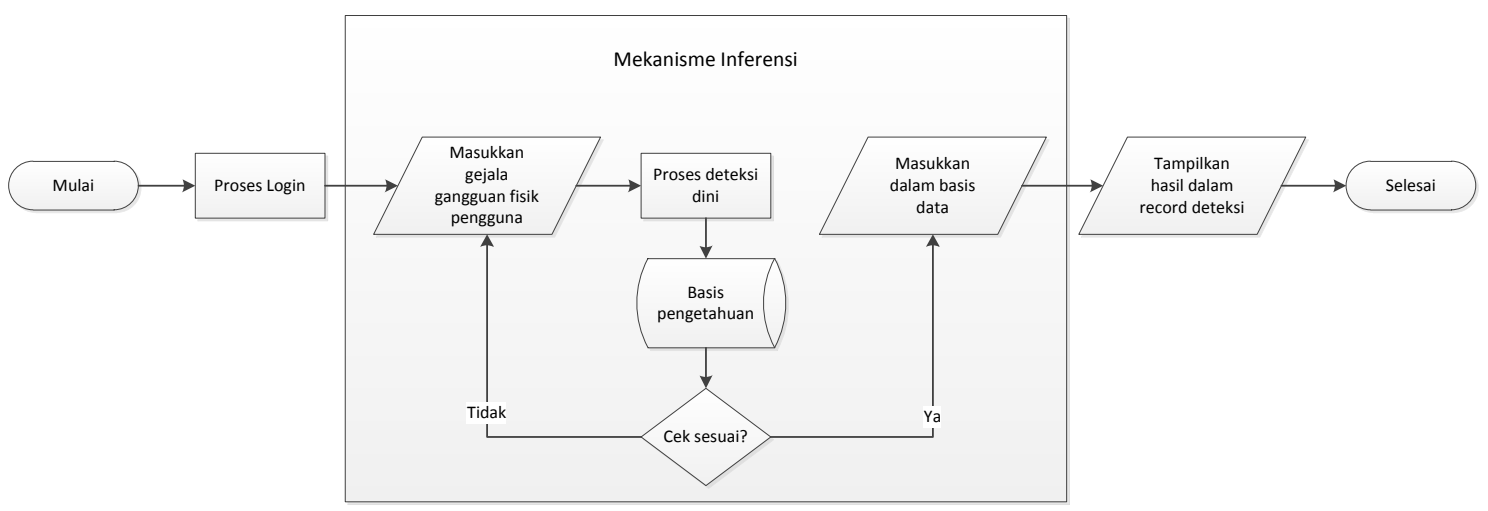

Gambar 1 Flowchart Mekanisme Inferensi Forward Chaining

Dari flowchart di atas, dapat dijelaskan bahwa mekanisme inferensi dengan metode forward chaining dimulai dengan user memberikan masukan berupa gejala gangguan fisik yang dialami. Kemudian sistem akan melakukan proses deteksi dini dan pengecekan masukan tersebut terhadap basis pengetahuan yang ada. Apabila data telah sesuai, maka data dimasukkan ke dalam basis data agar dapat digunakan untuk menarik suatu kesimpulan yang nantinya dapat ditampilkan kepada user melalui record hasil deteksi dini. Sebelum proses inferensi tersebut dilakukan, user perlu melakukan login terlebih dahulu. Tujuan proses login adalah agar setiap user dapat melihat record hasil deteksi dini yang pernah dilakukan melalui aplikasi ini.

\subsection{Pengguna Aplikasi}

Dalam pembuatan aplikasi deteksi dini defisiensi mineral mikro dalam tubuh berbasis web ini terdapat dua kategori pengguna, yaitu pengguna tidak terdaftar (guest) dan pengguna terdaftar (user). User dapat menggunakan seluruh fitur yang ada dalam aplikasi, sedangkan guest hanya dapat menggunakan beberapa fitur tertentu saja. Adapun fitur yang dapat digunakan oleh masing-masing pengguna tersebut dapat dilihat pada Gambar 2. 


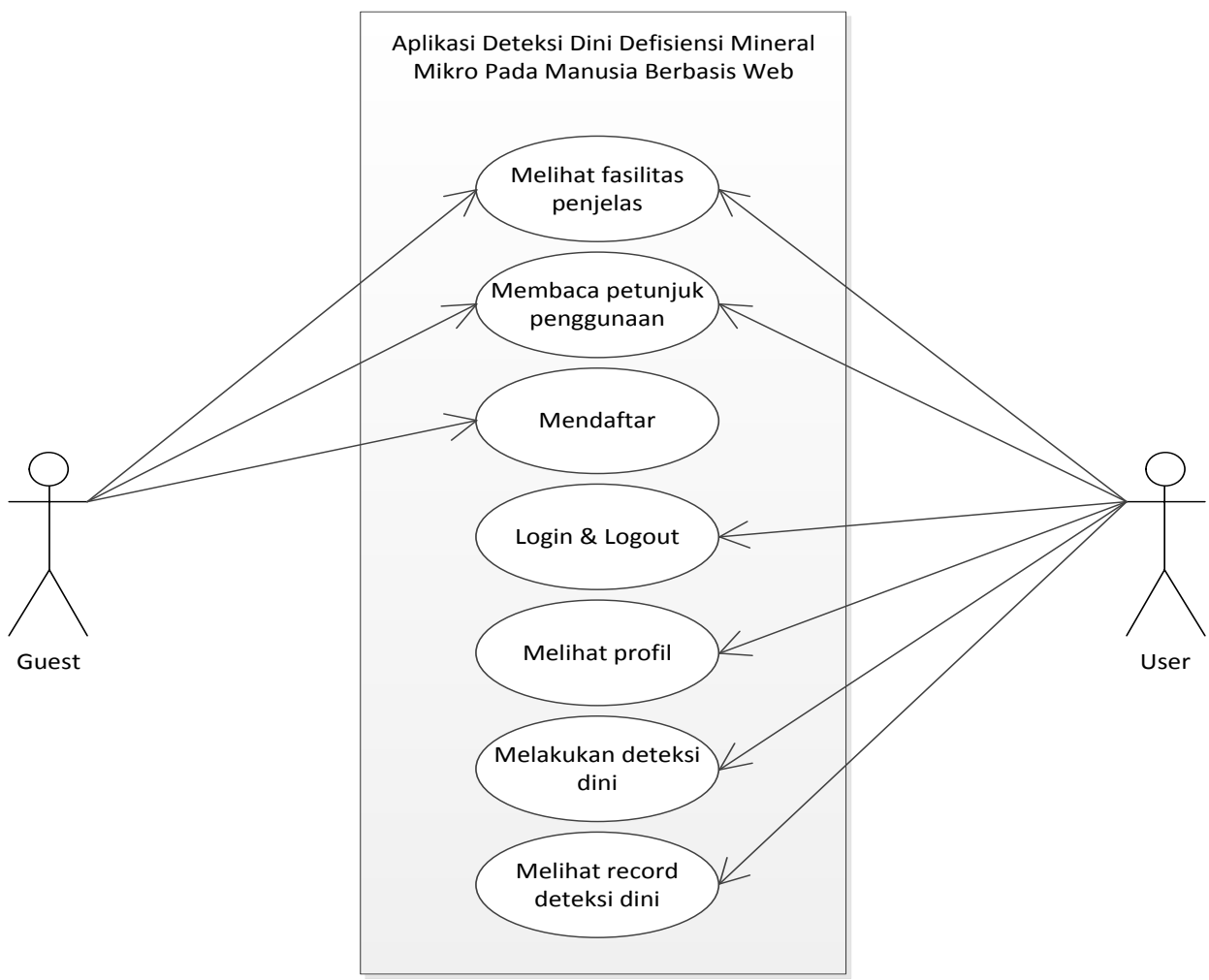

Gambar 2 Use Case Pengguna Aplikasi

\section{HASIL DAN PEMBAHASAN}

\subsection{Tampilan Aplikasi}

Adapun tampilan halaman aplikasi deteksi dini defisiensi mineral mikro dalam tubuh berbasis web sebagai hasil dari perancangan yang telah dilakukan ditunjukkan pada Gambar 3.

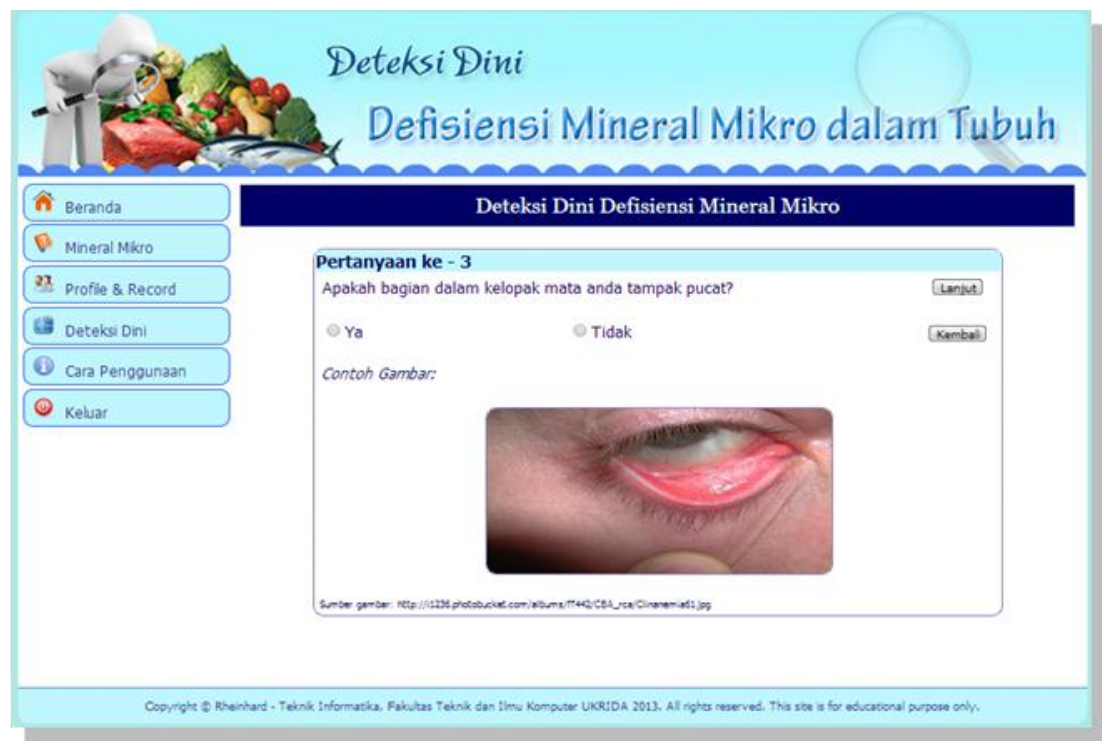

Gambar 3 Tampilan Halaman Deteksi Dini 
Gambar 3 merupakan tampilan halaman deteksi dini yang berisi sejumlah pertanyaan beserta gambar seputar gejala gangguan fisik yang harus dijawab oleh user dengan memilih salah satu dari dua pilihan jawaban Ya dan Tidak. Pertanyaan yang ditampilkan pada halaman ini akan dimulai pertama kali dari pertanyaan yang bersifat umum hingga ke pertanyaan yang bersifat khusus.

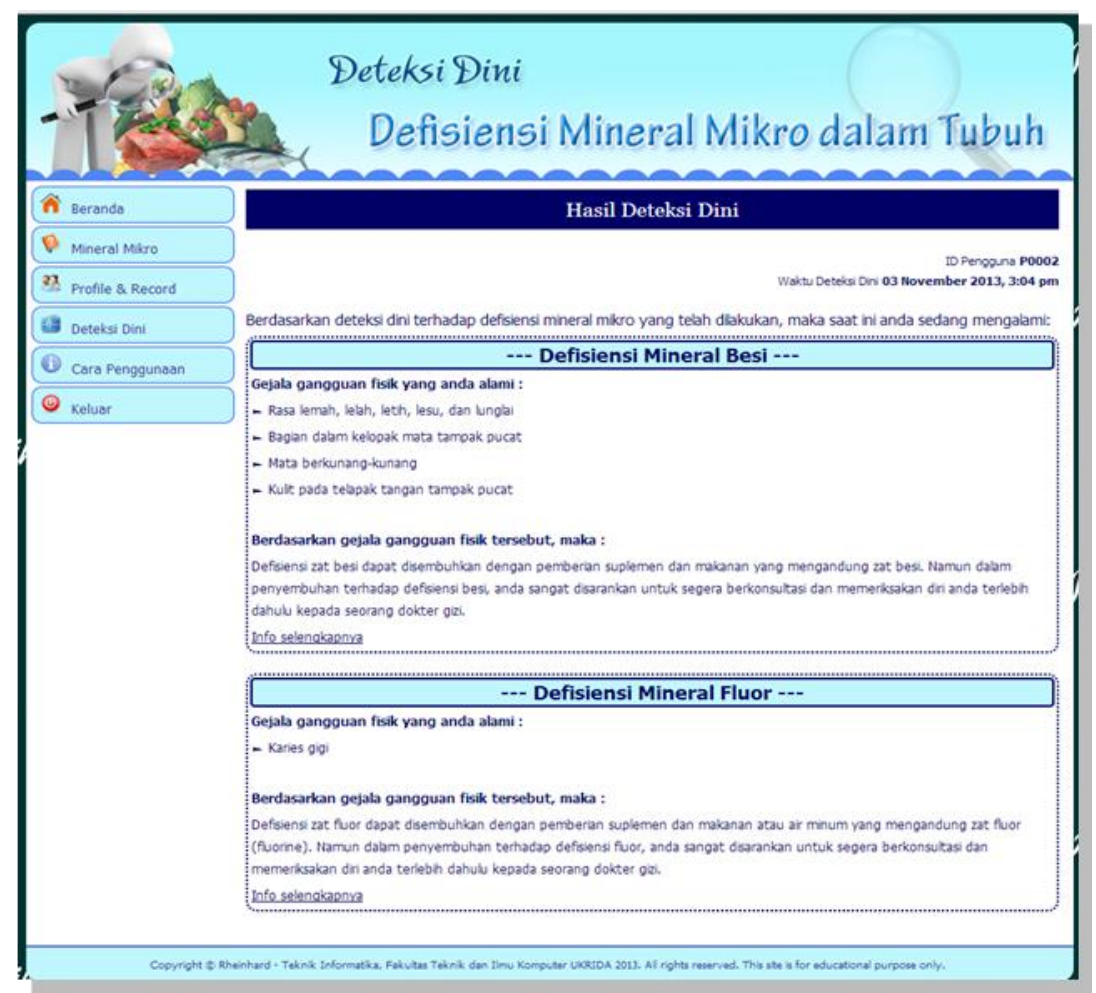

Gambar 4 Tampilan Halaman Hasil Deteksi Dini

Gambar 4 merupakan tampilan halaman yang berisi hasil deteksi dini yang telah dilakukan oleh user. Hasil deteksi dini tersebut berisi keterangan apakah pengguna mengalami defisiensi mineral mikro atau tidak.

\subsection{Evaluasi Aplikasi}

Pada tahap evaluasi, pengujian terhadap aplikasi dilakukan secara langsung kepada dokter spesialis gizi. Jika ditemukan rule dalam basis pengetahuan yang keliru, maka dilakukan perbaikan terhadap rule tersebut. Selain itu, pengujian terhadap aplikasi juga dilakukan dengan menggunakan data training dan penyebaran kuesioner ke beberapa responden. Pengujian terhadap aplikasi bertujuan untuk mengetahui apakah aplikasi tersebut telah mencapai tujuan dan manfaat yang diharapkan.

\subsubsection{Evaluasi Akuisisi Pengetahuan}

Evaluasi terhadap akuisisi pengetahuan dilakukan untuk mengetahui apakah hasil (output) yang dikeluarkan oleh sistem sesuai dengan hasil yang diperoleh langsung dari pakar gizi. Hal ini dilakukan dengan menguji aplikasi terhadap kasus dengan input sebagai berikut:

Gejala gangguan fisik yang dialami:

- Penglihatan mata sering berkunang-kunang

$\rightarrow$ kode: G001

- Bagian dalam kelopak mata tampak pucat

$\rightarrow$ kode: G002

- Mengalami 5L (letih, lesu, lemah, lelah, lunglai)

$\rightarrow$ kode: G005

- Kulit telapak tangan tampak pucat dari biasanya.

$\rightarrow$ kode: G006

IJCCS Vol. 8, No. 2, July 2014 : 213 - 222 
Dari gejala gangguan fisik yang dialami dalam kasus tersebut, maka sistem dapat mencatat relasi gangguan fisik tersebut dengan jenis defisiensi mineral mikronya, seperti yang ditunjukkan pada Tabel 3.

Tabel 3 Data Relasi Evaluasi Akuisisi

\begin{tabular}{|c|c|c|c|c|}
\hline \multirow{2}{*}{ Kode } & \multicolumn{4}{|c|}{ Jenis Defisiensi Mineral Mikro } \\
\cline { 2 - 5 } & Besi & Seng & Iodium & Fluor \\
\hline G001 & $\mathrm{x}$ & & & \\
\hline G002 & $\mathrm{x}$ & & & \\
\hline G005 & $\mathrm{x}$ & & & \\
\hline G006 & $\mathrm{x}$ & & & \\
\hline
\end{tabular}

Berdasarkan data relasi yang dicatat oleh sistem di atas, maka dapat dilihat bahwa gejala gangguan fisik tersebut terjadi karena defisiensi mineral besi. Sehingga, output yang dihasilkan oleh sistem adalah "Defisiensi Mineral Besi". Hal ini juga sependapat dengan dokter gizi yang mendiagnosa kasus tersebut bahwa berdasarkan gejala gangguan fisik yang dialami, maka diduga bahwa orang tersebut mengalami defisiensi mineral besi. Namun, sesungguhnya perlu dilakukan pemeriksaan lebih mendalam terhadap kasus tersebut oleh dokter gizi. Oleh karena itu, dapat disimpulkan bahwa melalui kasus tersebut, output yang dihasilkan oleh sistem sama dengan dengan hasil diagnosa yang dilakukan oleh dokter gizi.

\subsubsection{Data Testing}

Pengujjian dilakukan dengan mencocokkan hasil (output) yang diperoleh dari sistem berdasarkan kumpulan dari 100 sampel acak data masukan (input) dengan hasil yang didapat dari perhitungan manual melalui rules yang ada. Perhitungan akurasi tersebut dilakukan menggunakan rumus rata-rata biasa, yaitu:

$$
\text { Akurasi } \quad:=\frac{\text { Jumlah data yang sesuai }}{\text { banyak sampel data masukan }} * 100 \%
$$

Hasil dari pengujian yang dilakukan menunjukkan bahwa terdapat sebanyak 98 dari 100 data sampel yang benar (sesuai) dan 2 dari 100 data sampel yang salah (tidak sesuai), sehingga dapat disimpulkan bahwa:

$$
\text { Akurasi }=\frac{98}{100} * 100 \%=98 \% \text { aplikasi menghasilkan hasil yang valid }
$$

\subsubsection{Kuesioner}

Penyebaran kuesioner dilakukan pada tanggal 5 November 2013 terhadap 25 orang mahasiswa Ukrida dan 25 orang masyarakat yang tinggal di daerah Tangerang sebagai responden. Adapun hasil jawaban yang diberikan responden terhadap sejumlah pertanyaan yang diberikan dalam kuesioner tersebut adalah sebagai berikut: 
1) Kejelasan penyampaian informasi dalam aplikasi.

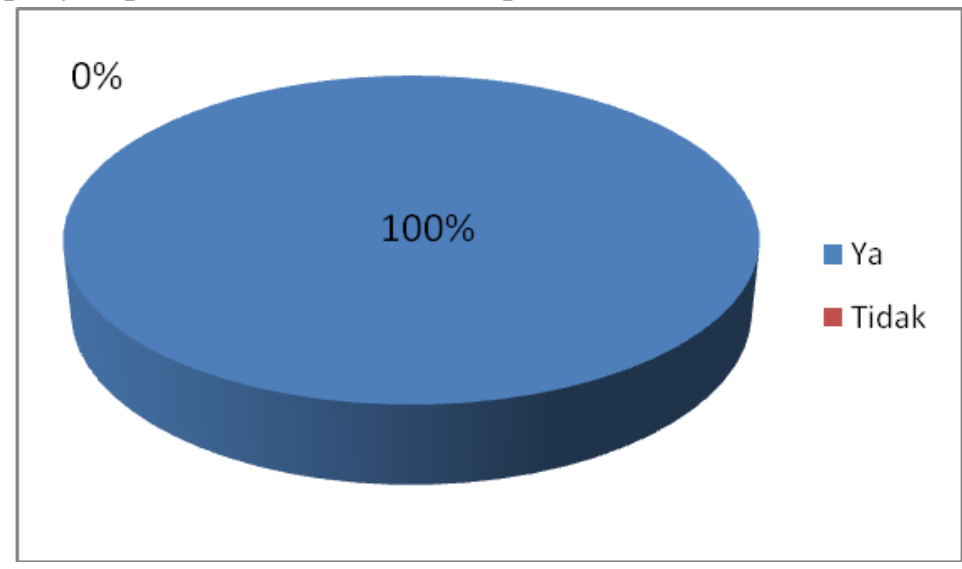

Gambar 5 Jawaban Kuesioner 1

2) Kemudahan penggunaan setiap fitur yang ada dalam aplikasi.

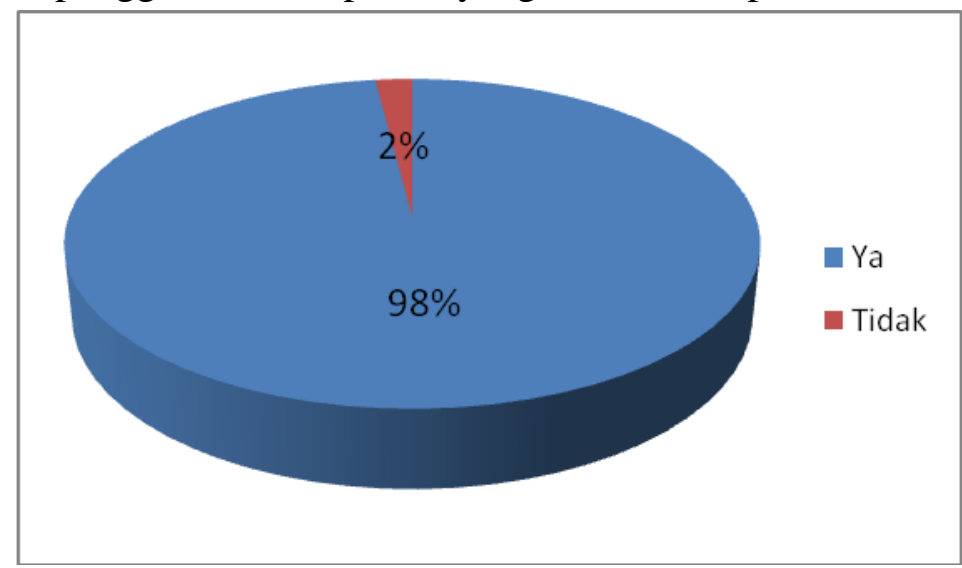

Gambar 6 Jawaban Kuesioner 2

3) Manfaat aplikasi untuk deteksi dini defisiensi mineral mikro serta penyampaian informasi seputar tindakan pencegahan dan pengobatannya.

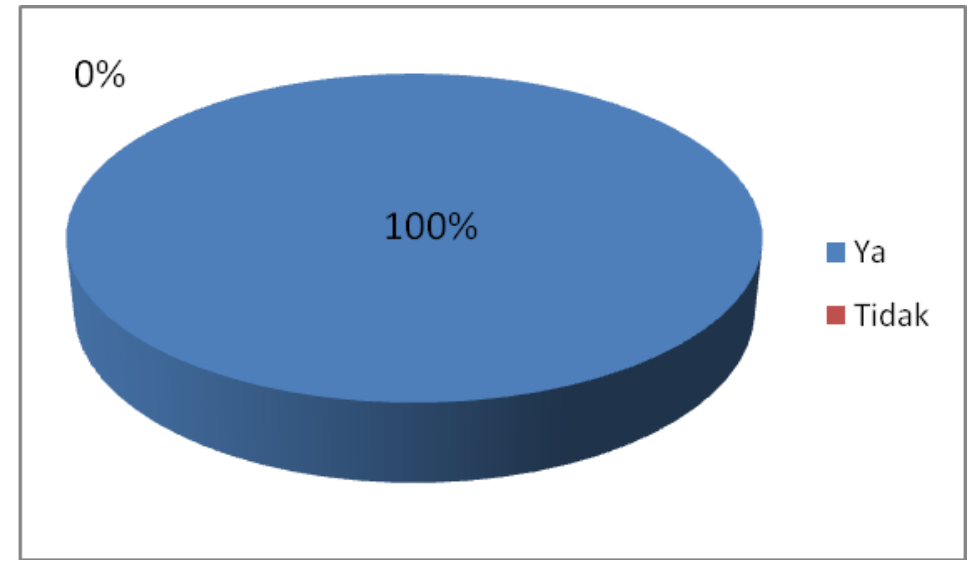

Gambar 7 Jawaban Kuesioner 3 


\section{KESIMPULAN}

Berdasarkan hasil pembahasan terhadap aplikasi deteksi dini defisiensi mineral mikro pada manusia berbasis web di atas, maka dapat ditarik kesimpulan bahwa:

1) Aplikasi ini hanya dapat membantu pengguna dalam mengetahui jenis defisiensi mineral mikro yang dialami secara dini. Hal ini dikarenakan hasil deteksi dini yang diberikan dalam aplikasi ini belum dapat dikatakan pasti, sehingga juga perlu dilakukan diagnosa secara mendalam oleh seorang dokter gizi secara langsung.

2) Aplikasi ini dapat memberikan pengetahuan kepada pengguna, khususnya masyarakat awam mengenai mineral mikro, mulai dari peranannya dalam tubuh, gejala dan pencegahan defisiensi, hingga sumber makanannya.

\section{SARAN}

Aplikasi deteksi dini defisiensi mineral mikro pada manusia berbasis web ini masih belum sempurna. Oleh karena itu ada beberapa saran yang dapat meningkatkan kualitas aplikasi deteksi dini ini dalam pengembangannya ke depan, yaitu antara lain:

1) Membuat aplikasi ini menjadi lebih dinamis melalui menu yang hanya dapat digunakan oleh pakar atau pun pengembang untuk melakukan update terhadap rules atau basis pengetahuan yang ada dalam aplikasi.

2) Menambahkan fitur dalam aplikasi agar juga dapat mendeteksi defisiensi untuk jenis zat gizi yang lainnya, serta juga dapat mendeteksi masalah terhadap kelebihan jenis zat gizi tertentu.

3) Membuat aplikasi mampu melakukan pengolahan data dan rules dengan metode lain, seperti Fuzzy atau Certainty Factor.

4) Penelitian lebih lanjut diharapkan membuat aplikasi ini juga dapat diakses dengan mudah melalui perangkat mobile oleh karena melihat perkembangan teknologi mobile yang terjadi saat ini.

\section{DAFTAR PUSTAKA}

[1] Almatsier, S, 2010, Prinsip Dasar Ilmu Gizi, Gramedia Pustaka Utama, Jakarta.

[2]WHO, 2004, Iodine Status Worldwide, http://www.who.int/nutrition/publications/micronutrients/iodine_deficiency/9241592001/en/i ndex.html, diakses tgl 10 Juni 2013.

[3]Kementrian Kesehatan RI, 2011, Diskusi Pakar Penanggulangan Masalah GAKY, http://gizi.depkes.go.id/diskusi-pakar-penanggulangan-masalah-gaky, diakses $\quad \operatorname{tgl} 14$ September 2013.

[4]Nurwidiawati, A dan Sumaningsih, R. 2010, Hubungan Antara Defisiensi Yodium Dengan Prestasi Belajar, Jurnal Penelitian Kesehatan Suara Forikes, No. 1, Vol. 1, 47-50, http://static.schoolrack.com/files/100398/295411/volume1 nomor1.pdf\#page=49.

[5]Bararah, V.F. 2012, Ini Dia Status Gizi Anak Indonesia, 
http://health.detik.com/read/2012/11/14/175540/2091936/1301/ini-dia-status-gizi-anakindonesia?1992205755, diakses tgl 14 September 2013.

[6]Candra, A. 2012, Jangan Sampai Anak Kekurangan Zinc, http://health.kompas.com/read/2012/08/01/20314692/Jangan.Sampai.Anak.Kekurangan.Zinc , diakses tgl 01 Juni 2013.

[7]Jones, S. 2005, The Effective Use of Fluorides in Public Health, www.who.int/bulletin/volumes/83/9/670.pdf, diakses tgl 13 September 2013.

[8]Hamdani, 2010, Sistem Pakar Untuk Diagnosa Penyakit Mata Pada Manusia, Jurnal Informatika Mulawarman, No. 2, Vol. 5, 13-21, http://informatikamulawarman.files.wordpress.com/2010/07/02-jurnal-informatikamulawarman-juni2010-v-1-1.pdf.

[9]Patra, P. Kumar, S. Sahu, D.P. dan Mandal, I. 2010, An Expert System for Diagnosis of Human Disease, International Journal of Computer Applications, No. 13, Vol. 1, 71-73, http://www.researchgate.net/publication/43763822 An Expert System for Diagnosis Of Human_Diseases/file/9fcfd50e7f9c539577.pdf.

[10]Putra, E.R.Y. Wafa, Z. dan Mardison, 2013, Perancangan Sistem Pakar Untuk Mendiagnosa Penyakit Anemia, Jurnal Online UPI-YPTK Padang, ID 377, http://www.upiyptk.ac.id/ejournal/File_Jurnal/Jurnal\%20Sistem\%20Pakar\%20Anemia.pdf.

[11]Parno dan Qoirina, I. 2012, Aplikasi Sistem Pakar Untuk Mendeteksi Status Gizi dan Psikologis Anak, Konferensi Nasional Sistem Informasi STMIK - STIKOM Bali, No. Makalah 232, Bali, Februari 23-25. 